
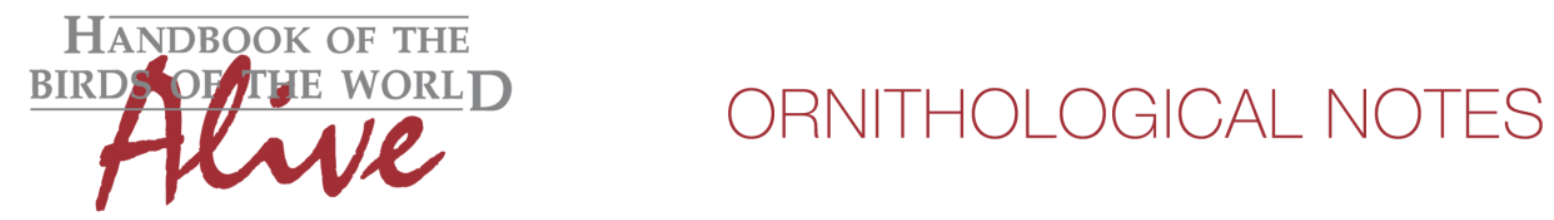

\title{
Notes on the vocalizations of Curve-billed Scythebill (Campylorhamphus procurvoides)
}

Peter Boesman

In the following we briefly analyze and compare voice of the different races of Curve-billed Scythebill (Campylorhamphus procurvoides). We also try to quantify the extent of any vocal differences using the criteria proposed by Tobias et al. (2010), as a support for taxonomic review. We have made use of sound recordings available on-line from Xeno Canto (XC) and Macaulay Library (ML).

We have used the taxonomy in which the following taxa are recognized: procurvoides, sanus, gyldenstolpei, probatus, cardosoi and multostriatus.

There are few recordings available on-line for $C$. procurvoides, with only ssp. procurvoides and cardosoi slightly better represented. It is however clear that within most if not all taxa, besides short call notes, there is 'the most extensive or elaborated vocalization' which could be called 'typical loudsong' and then there are several variants (shorter versions without acceleration, versions lacking the long introductory note, etc.). When including these variants into the analysis, at least the basic parameters pace, frequency, etc. become smudged and differences become fuzzy. When we limit the analysis to 'typical loudsong' (obviously only based on just a few samples and thus somewhat selective), differences are clearer and could be summarized as follows:

procurvoides: a series of c. 15-20 notes starting with several long notes at a rather flat pitch, gradually accelerating and leading to a fast rising series of short notes:

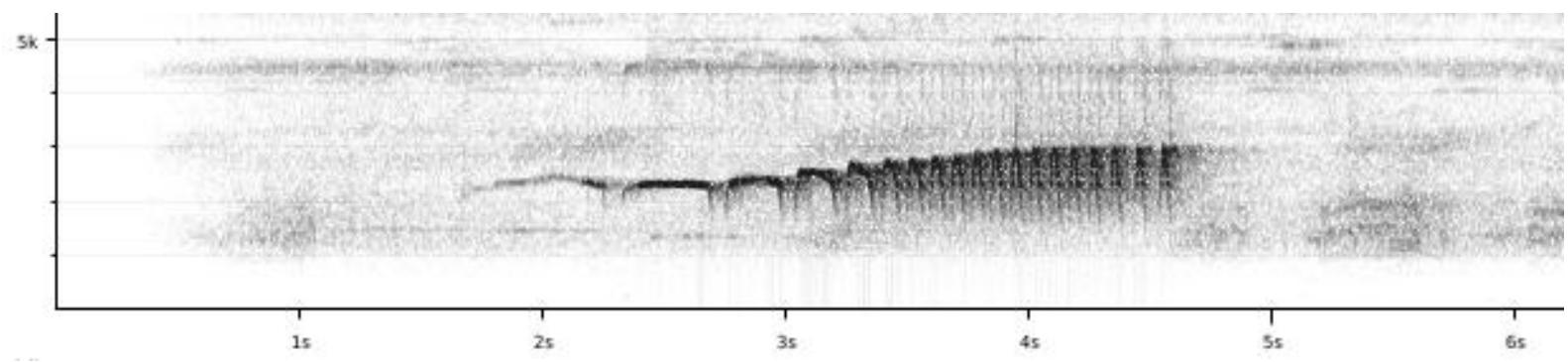

sanus: virtually identical to procurvoides (at most delivered slightly slower and rising less towards end):

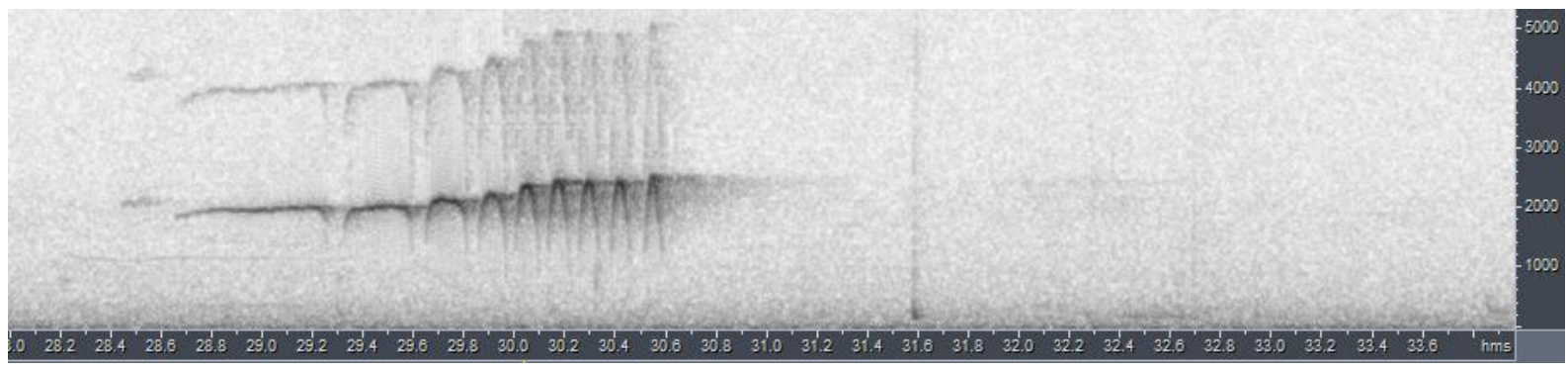




\section{HANDBOOK OF THE

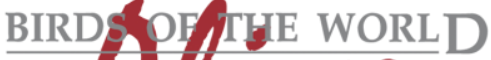 Alve}

\section{ORNITHOLOGICAL NOTES}

gyldenstolpei: similar to the previous 2 taxa, a series of c. 10-15 notes starting with several long notes at a rising pitch, gradually accelerating and leading to a fast slightly rising series of short notes (but end pace slower than previous):

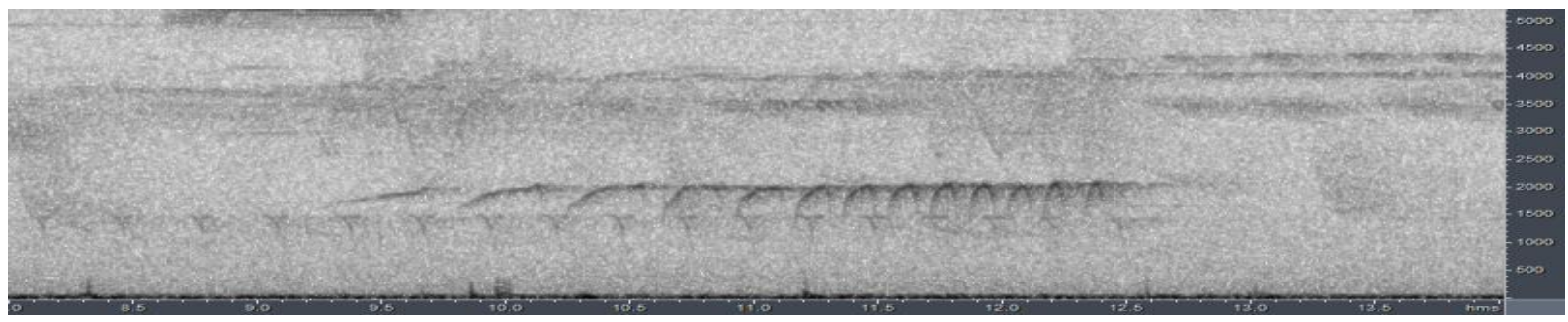

probatus: a single emphasized overslurred long note, abruptly followed by a long fast series of nearly identical short notes:

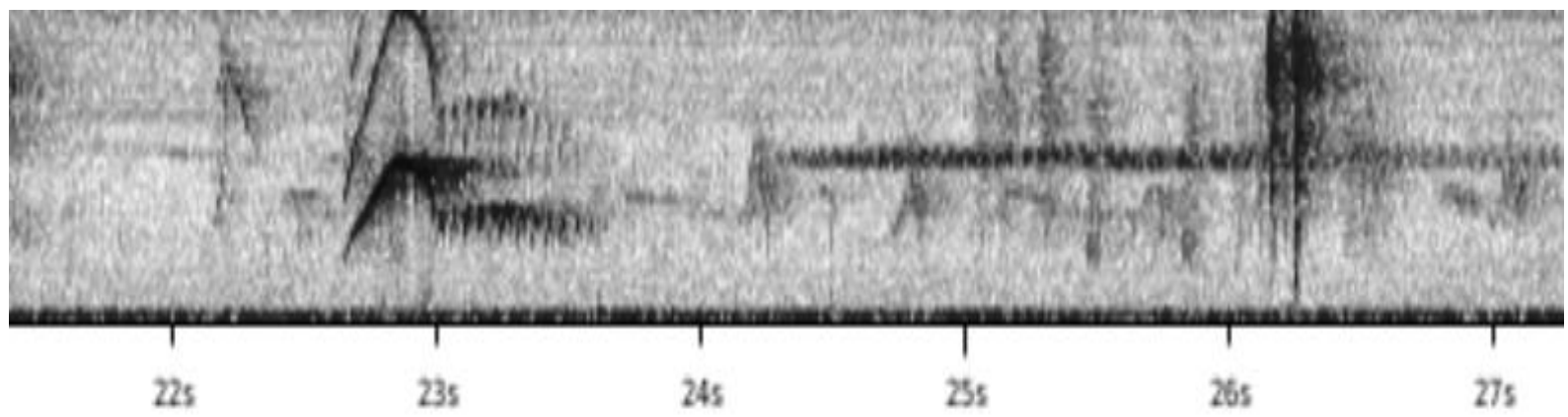

cardosoi: nearly identical to probatus (at most with slight difference in average length/pitch introductory note, but probably even with larger number of samples not statistically significant):

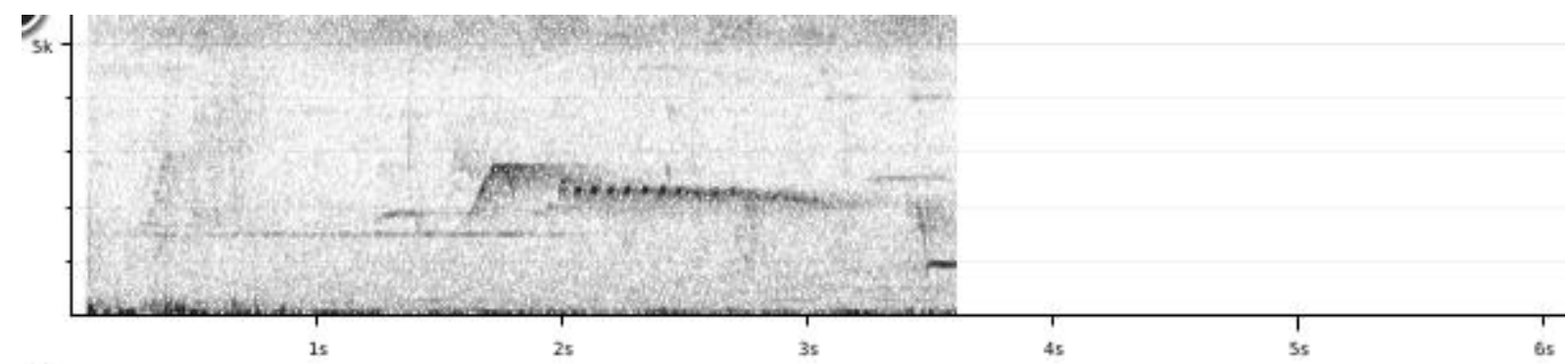

multostriatus: a series of c. 7-10 notes, with little variation in note length and pitch:

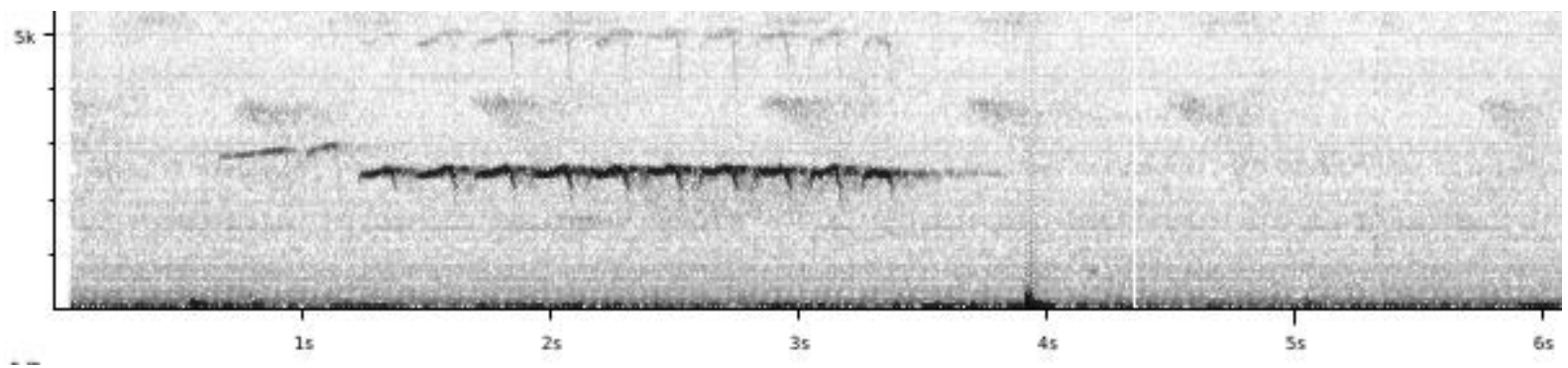



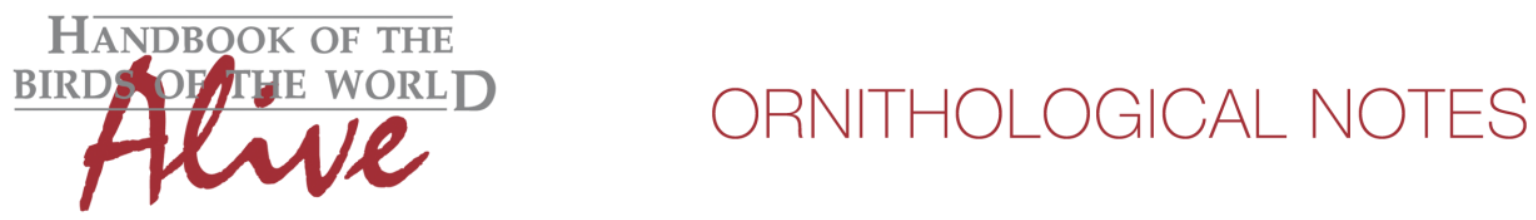

This suggests a logical clustering based on voice into three groups:

Group 1: procurvoides/sanus/gyldenstolpei: a series of c. 10-20 notes starting with several long notes, gradually accelerating and leading to a fast, usually rising series of short notes. Compared to probatus/cardosoi, main quantified differences are length ratio first/second note (score 3 ), pitch ratio first/second note (score 2 ), fastest pace (score 2), which would lead to a total score of 5 using Tobias criteria.

Group 2: probatus/cardosoi: a single emphasized overslurred long note, abruptly followed by a long fast series of nearly identical short notes.

Group 3: multostriatus: a series of c. 7-10 notes, with little variation in note length and pitch.

Compared to probatus/cardosoi, main quantified differences are length ratio first/last note (score 3), fastest pace (score 3), resulting in a total score of 6.

Compared to procurvoides/sanus/gyldenstolpei main quantified differences are length ratio first/last note (score 3), pitch ratio first/last note (score 2), resulting in a total score of 5.

(scores of different races within each group are much smaller, presumably at most 1-2)

In Portes et al. (2013), Red-billed Scythebill C. trochilirostris seems to be genetically clustered in the present species complex, closest to probatus/cardosoi.

C. trochilirostris in itself is a complex of many taxa with different vocalizations. Lumping this total group with probatus/cardosoi would thus vocally make no sense at all. But then maybe one or more taxa of $C$. trochilirostris are close enough. I have therefore checked if there are any recordings of $C$. trochilirostris which closely resemble the loudsong of probatus/cardosoi. Of the 105 recordings on XC, there is however none that has a long initial note followed by a descending series of notably shorter notes.

At the other hand, all trochilirostris taxa $\mathrm{S}$ of the Amazon (hellmayri, major, devius and lafresnayanus) seem to have a very similar vocalization (with a long call which is fairly close to procurvoides). It may thus well be that this group, which I believe does not overlap geographically with any of the 'Curvebilled' taxa, is closer related to the latter than to northern Red-billed Scythebills. Coincidently, for the molecular analysis in Portes et al., all taxa of trochilirostris sampled are apparently from $\mathrm{S}$ of the Amazon river ! If samples of taxa $\mathrm{N}$ of the Amazon would have been taken as well, this would sure have given more confidence about the relationships in the dendrogram, or would have changed the picture.

C. trochilirostris is probably just like the Curve-billed group a combination of several groups/species.

Vocally there are apparently 3 groups:

- venezuelensis of the northern region (presumably with brevipennis)

- thoracicus/napensis

- hellmayri, major, devius, trochilirostris and lafresnayanus

This would obviously need a separate analysis, in order to prove the above is more than just speculation. 

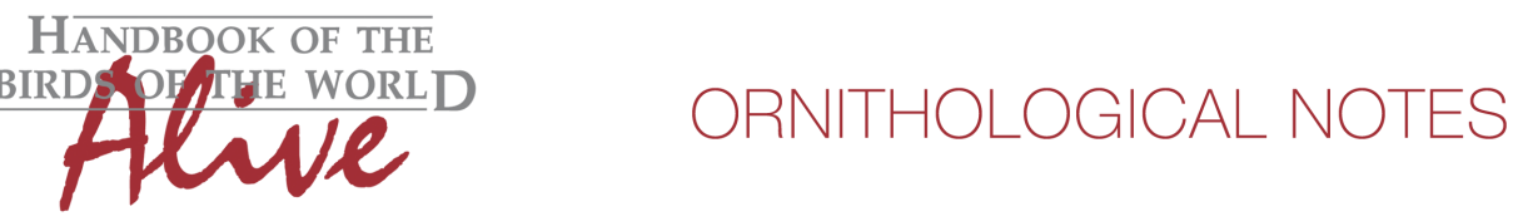

This note was finalized on 31st March 2015, using sound recordings available on-line at that moment. We would like to thank in particular the many sound recordists who placed their recordings for this species on XC and ML.

\section{References}

Portes, Aleixo, Zimmer, Whittaker, Weckstein, Gonzaga, Ribas, Bates \& Lees (2013). A new species of Campylorhamphus (Aves: Dendrocolaptidae) from the Tapajós - Xingu interfluve in Amazonian Brazil. HBW SV: 258-262.

Tobias, J.A., Seddon, N., Spottiswoode, C.N., Pilgrim, J.D., Fishpool, L.D.C. \& Collar, N.J. (2010). Quantitative criteria for species delimitation. Ibis 152(4): 724-746.

\section{Recommended citation}

Boesman, P. (2016). Notes on the vocalizations of Curve-billed Scythebill (Campylorhamphus procurvoides). HBW Alive Ornithological Note 83. In: Handbook of the Birds of the World Alive. Lynx Edicions, Barcelona. (retrieved from http://www.hbw.com/node/931977 on 16 July 2016). 